\title{
Early-Pregnancy Changes in Maternal Lipid Profile in Women with Recurrent Preeclampsia and Women with Normal Pregnancy
}

\author{
Sumaya T. Saihood*
}

FICOG

\section{$\underline{\text { Abstract }}$}

JFac Med Baghdad 2017; Vol.59, No .2 Receive Jan. 2017 Accepted April.2017

Background: According to the current knowledge, changes in lipid profile in pregnancy is a major contributor in the pathogenesis of preeclampsia. The present study was designed to compare the changes in lipid profile in normal pregnancy and in patients with history of recurrent pre-eclampsia (PE).

Objective: Assessment the relationship between lipid profiles changes in women with history of recurrent preeclampsia in comparison to normal pregnancy in early pregnancy.

Patients and Methods: Measurement of lipid profile changes in women with history of recurrent preeclampsia (more than two preeclampsia in previous pregnancies) at 12 to 16 weeks of pregnancy and compared to normal pregnancy as a control group who does not have history of preeclampsia also early in pregnancy

Results: The patients with history of recurrent Preeclampsia had significantly higher mean total cholesterol level compared to controls $(216.1 \pm 25.5 \mathrm{mg} / \mathrm{dl})$ and $(195.6 \pm 23.2 \mathrm{mg} / \mathrm{dl})$, respectively, $(\mathrm{P}<0.05)$. The mean HDL cholesterol $(\mathrm{HDL}-\mathrm{C})$ level was significantly lower in PE group $(49.3 \pm 9.2$ $\mathrm{mg} / \mathrm{dl})$ than controls $(52.2 \pm 8.4 \mathrm{mg} / \mathrm{dl}),(\mathrm{P}<0.05)$. The mean level of LDL cholesterol was $(122.3 \pm 28.7)$ $\mathrm{mg} / \mathrm{dl}$ in PE group and it was significantly higher than the $(108.6 \pm 26.8 \mathrm{mg} / \mathrm{dl})$ of controls, $(\mathrm{P}<0.05)$. Similarly, the mean VLDL cholesterol was also higher in women with history of recurrent preeclampsia than control group, $(44.8 \pm 12.6)$ vs. $(34.8 \pm 7.3) \mathrm{mg} / \mathrm{dl}$, respectively, $(\mathrm{P}<0.05)$. The Triglycerides $(\mathrm{TG})$ was also elevated in women with history of recurrent preeclampsia where the mean TG level was (224.2 $\pm 63.1 \mathrm{mg} / \mathrm{dl})$ compared to $(174.6 \pm 36.3 \mathrm{mg} / \mathrm{dl})$ in controls, $(\mathrm{P}<0.05)$.

Conclusion: This study showed that the women who have history of recurrent preeclampsia had disturbed lipid profile (increased levels of total TC, TG, VLDL-C and LDL-C concentration) in addition to decrease the high density lipoprotein cholesterol (HDL-C) level in subsequent pregnancy compared to normal pregnancy.

Keywords: Preeclampsia, Changes in lipid profile during pregnancy

\section{Introduction:}

As pregnancy progresses, a well-integrated metabolic shift occurs to ensure an adequate supply of nutrients to a constantly feeding fetus from an intermittently fasting and feeding mother. During early pregnancy, maternal metabolic environment is modified by a rise in serum levels of estrogen and progesterone, pancreatic beta-cell hyperplasia occurs and there is an increase in secretion of insulin (1). Hyperinsulinemia leads to an increase in peripheral glucose utilization, a decline in fasting plasma glucose levels, increased tissue storage of glycogen, increased storage of fats and decreased lipolysis (2). It is known that high concentrations of many of the steroids occur as normal pregnancy advances. Since cholesterol is the source of most of the steroids found in increased amounts in the circulation of normal pregnant patients, the part played by lipid metabolism in pregnancy, becomes all the more intriguing - as cholesterol is a major factor for the development of atherosclerosis (2). Chauffard in 1911 undertook the first chemical study of blood lipids during pregnancy and suggested that an increase occurs in the cholesterol level (3).

*Dept. Of Obst. \& Gyne. College of Medicine, Tikrit University amasts006@yahoo.com
With the development of more techniques various studies observed an increase in various lipid fractions, though the increase was neither consistent in time of appearance nor proportion of changes in various fractions. Most authors believe that the increase in blood lipids is related to the requirements of the fetus and to development of the mammary apparatus (4). Preeclampsia is a pregnancy specific disorder, characterized by pregnancy induced hypertension (BP $\geq 140 / 90 \mathrm{~mm} \mathrm{Hg}$ ) on two occasion, at least 6 hours apart and proteinuria of $\geq 300 \mathrm{mg} / 24$ hours or $\geq 1+$ dipstick after 20 weeks of gestation in previous normotensive women. It is the most common medical complication of pregnancy, whose incidence has continued to increase worldwide (5). It results in an increased risk for intrauterine growth restriction, prematurity, and death and it is also recognized as a major risk factor for cardiovascular disease later in life for both the woman and her child(6). There is no effective therapy for the management of preeclampsia, and the only cure is to deliver the infant (7). Preeclampsia is distinguished from the other hypertensive disorders of pregnancy by new onset hypertension and new onset proteinuria without seizure activity after 20 weeks of gestation. (8, 9, 10). During normal pregnancies (without accompanying morbidities such as gestational 


\section{Preeclampsia and Women with Normal Pregnancy}

diabetes or preeclampsia), total cholesterol levels increase by $50 \%$, and triglyceride levels rise markedly by 2 to 4 fold. Moreover, high-density lipoprotein cholesterol (HDL-C) levels increase by $30 \%$, while low-density lipoprotein-cholesterol (LDL-C) levels increase by $50 \%$. These changes in lipid metabolism during pregnancy promote the accumulation of maternal fat stores in the first twothirds of gestation in order to serve as a source of calories for the mother and fetus in late pregnancy and during lactation. Cholesterol is also necessary for placental steroid synthesis, and triglycerides are used for placental oxidation and membrane formation (11, 12) Reversal of the hyperlipidemia of pregnancy begins within hours of delivery and is essentially complete by $6-10$ weeks postpartum (13).

\section{Patients and Methods:}

The patients attended Tikrit teaching hospital at outpatient department from Feb. 2014 to Jun.2014.Then those taken from Medical city hospital from Aug.2014 to Oct 2014 and those patient taken from Samarra city hospital from Oct.2014 to Dec.2014. The participant divided in to 2 groups, eighty three women with history of recurrent preeclampsia( cases - PE group) and eighty nine normal pregnant women. The inclusion criteria was singleton pregnancy and women with history of recurrent preeclampsia. Those who are excluded were hypertensive women or use of anti-hypertensive treatment, twin or higher multiple pregnancy, and those with history of gestational hypertension. At arrival, full history was taken from each patient, general and obstetrical examination is carried out, maternal vital signs ( blood pressure, pulse rate, respiratory rate, and temperature) are taken, and approved previous history of recurrent preeclampsia by patient doctor card and previous investigations Venous blood was drawn from pregnant women with history of recurrent preeclampsia at 12-16 weeks and from normal pregnant women after overnight fasting. Each serum sample was evaluated for total cholesterol $(\mathrm{mg} / \mathrm{dl})$, triglyceride $(\mathrm{mg} / \mathrm{dl})$, and HDLcholesterol (mg/dl) using diagnostic kit: Additional

\section{Table 1: Demorphic and clinical characteristics of studied group}

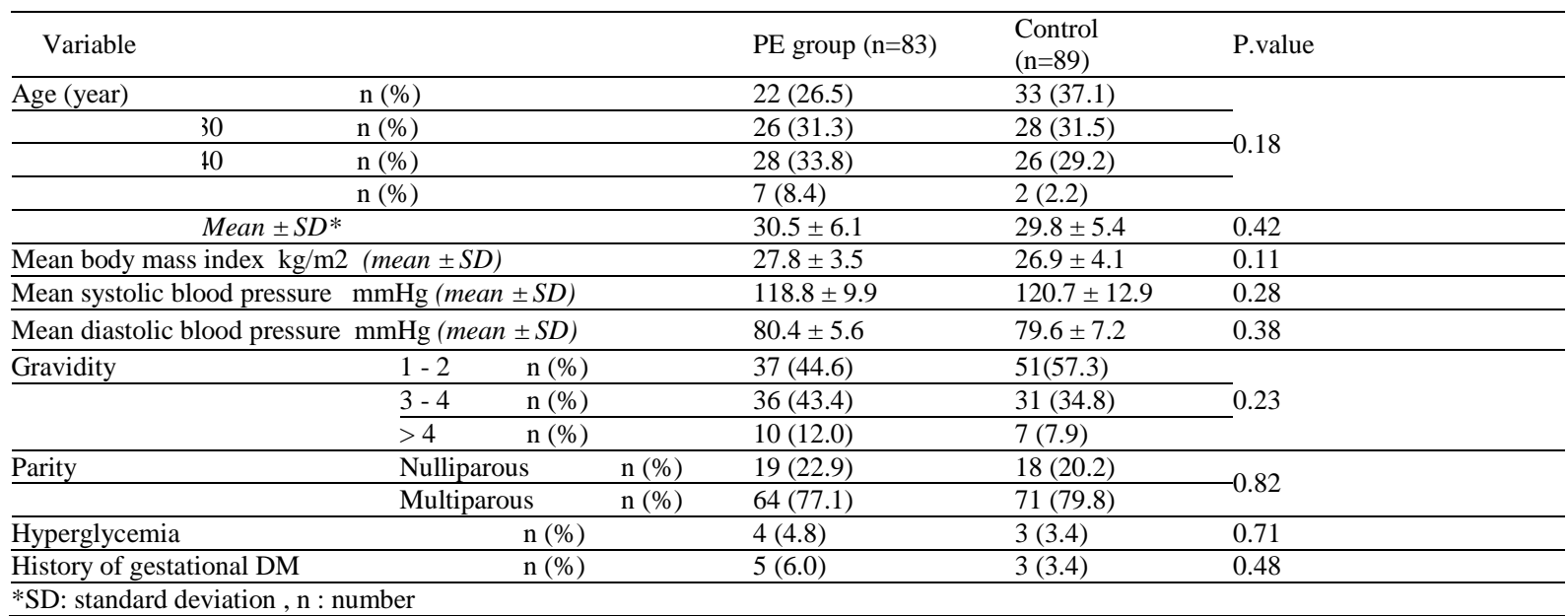

parameters were LDL-cholesterol $(\mathrm{mg} / \mathrm{dl})$ and VLDL- cholesterol (mg/dl) using Friedewald formula Glucose also calculated.

\section{Statistical analysis:}

Descriptive statistics were presented as mean, standard deviation (SD), frequencies (No.) and proportions (\%). Chi square and Fishers exact test were used alternatively to compare frequencies, when applicable to estimate the relationship between variables. Multiple logistic regression analysis (binary model) was used for further analysis of the correlation between variables. Odds ratio (as an estimator for the risk) was calculated, the significant Odds ratio and more than 1 , indicated that the factor present in study group is a risk factor might associated with the occurrence of the outcome the larger odds ratio of a factor, indicated the higher risk level due to the presence of that factor. Level of significance (p. value) was set at $\leq 0.05$ to be significant

\section{Results:}

A total of 100 pregnant women at the gestational age of $12-16$ weeks with history of recurrent preeclampsia (PE group) in addition to 100 women with normal pregnancy (control group) were enrolled in this case control study, 17 women in cases group and 11 in control group were missed to follow up resulted in a net sample of 83 women in (PE group) and 89 in control group. The baseline clinical and demographic characteristics of the studied groups are shown in (table 1). The mean age of women in PE and control groups was $(30.5 \pm 6.1)$ and $(29.8 \pm 5.4)$ years, respectively. The Mean body mass index was $27.8 \pm$ $3.5 \mathrm{~kg} / \mathrm{m} 2$ in PE group and $26.9 \pm 4.1 \mathrm{~kg} / \mathrm{m} 2$ in controls. Hyperglycemia was found in only 7 women; 4 (4.8\%) PE women and 3 (3.4\%) controls. History of gestational DM was found in $5(6 \%) \mathrm{PE}$ women and 3 (3.4\%) controls. However, no statistically significant differences between both studied groups had been found in the baseline clinical and demographic parameters, in all comparison $\mathrm{P}>0.05$, (Table 1). 
Preeclampsia and Women with Normal Pregnancy

As it shown in table2, patients with history of recurrent preeclampsia (PE group) had significantly higher mean total cholesterol level compared to controls $(216.1 \pm 25.5 \mathrm{mg} / \mathrm{dl})$ and $(195.6 \pm 23.2$ $\mathrm{mg} / \mathrm{dl})$, respectively, $(\mathrm{P}<0.05)$. The mean $\mathrm{HDL}$ cholesterol (HDL-C) level was significantly lower in PE group $(49.3 \pm 9.2 \mathrm{mg} / \mathrm{dl})$ than controls $(52.2 \pm 8.4$ $\mathrm{mg} / \mathrm{dl}),(\mathrm{P}<0.05)$. The mean level of LDL cholesterol was $(122.3 \pm 28.7) \mathrm{mg} / \mathrm{dl}$ in PE group and it was significantly higher than the $(108.6 \pm 26.8 \mathrm{mg} / \mathrm{dl})$ of controls, $(\mathrm{P}<0.05)$. Similarly, the mean VLDL cholesterol was also higher in PE than control group, $(44.8 \pm 12.6)$ vs. $(34.8 \pm 7.3) \mathrm{mg} / \mathrm{dl}$, respectively, $(\mathrm{P}<0.05)$. The Triglycerides (TG) was also elevated in PE group where the mean TG level was $(224.2 \pm$ $63.1 \mathrm{mg} / \mathrm{dl})$ compared to $(174.6 \pm 36.3 \mathrm{mg} / \mathrm{dl})$ in controls, $(\mathrm{P}<0.05)$. (Table2)

Table2. Comparison of mean levels of lipid profile of the studied groups.

\begin{tabular}{|c|c|c|c|c|}
\hline Serum lipid & & $\begin{array}{l}\text { PE group } \\
(n=83)\end{array}$ & $\begin{array}{c}\text { Control } \\
(n=89)\end{array}$ & P.value* \\
\hline \multirow[t]{2}{*}{ Total cholesterol mg/dl } & mean $\pm S D$ & $216.1 \pm 25.5$ & $195.6 \pm 23.2$ & 0.001 \\
\hline & Range & $163-272$ & $154-261$ & \\
\hline \multirow[t]{2}{*}{ HDL cholesterol mg/dl } & mean $\pm S D$ & $49.3 \pm 9.2$ & $52.2 \pm 8.4$ & 0.026 \\
\hline & Range & $34-64$ & $38-62$ & \\
\hline \multirow[t]{2}{*}{ LDL cholesterol mg/dl } & mean $\pm S D$ & $122.3 \pm 28.7$ & $108.6 \pm 26.8$ & 0.002 \\
\hline & Range & $73-197$ & $73-182$ & \\
\hline \multirow[t]{2}{*}{ VLDL cholesterol $\mathrm{mg} / \mathrm{dl}$} & mean $\pm S D$ & $44.8 \pm 12.6$ & $34.8 \pm 7.3$ & 0.001 \\
\hline & Range & $28-64$ & $24-53$ & \\
\hline \multirow[t]{2}{*}{ Triglycerides mg/dl } & mean $\pm S D$ & $224.2 \pm 63.1$ & $174.6 \pm 36.3$ & 0.001 \\
\hline & Range & $139-320$ & $120-269$ & \\
\hline
\end{tabular}

$* \mathrm{P}<0.05$ significant

Further analysis was performed to assess the changes in lipid profile in both groups; the multiple logistic regression (binary) test was conducted for adjustment of any possible confounders, the results of this analysis are shown in table 3 , where only three variables appeared to be associated with serum lipid levels, the more effect was found to the

previous pre-eclampsia, $(\mathrm{OR}=2.60, \quad \mathrm{P}=0.02)$ followed by fasting blood glucose (OR 1.19, $\mathrm{P}=0.04)$ and systolic blood pressure $(\mathrm{SBP}),(\mathrm{OR}=1.04$, $\mathrm{P}=0.05)$. Nonetheless, these findings indicated that previous preeclampsia status was an independent risk factor for dyslipidemia and early undesirable changes in lipid profile which might be a risk factor to develop preeclampsia

Table 3. Results of multiple logistic regressions for the risk factors

\begin{tabular}{|c|c|c|c|c|}
\hline Risk factors associated with serum variability & ß & Odds ratio $(\mathrm{OR})$ & 95\% C.I.for OR & P.value* \\
\hline Preeclampsia & 0.96 & 2.60 & $1.15-5.87$ & 0.02 \\
\hline FBS & 0.09 & 1.19 & $1.00-1.18$ & 0.04 \\
\hline SBP & 0.04 & 1.04 & $1.00-1.08$ & 0.05 \\
\hline DBP & 0.04 & 0.96 & $0.90-1.03$ & 0.28 \\
\hline Age & 0.03 & 0.97 & $0.89-1.06$ & 0.47 \\
\hline History of Gestational HT & 0.79 & 0.45 & $0.05-3.82$ & 0.47 \\
\hline History of Gestational DM & 0.20 & 1.22 & $0.66-2.31$ & 1.00 \\
\hline Parity & 0.14 & 1.14 & $0.44-2.98$ & 0.78 \\
\hline Gravidity & 0.10 & 0.91 & $0.42-1.95$ & 0.80 \\
\hline Hyperglycemia & 0.17 & 1.18 & $0.47-3.12$ & 1.00 \\
\hline
\end{tabular}

\section{Discussion}

Most studies evaluating the HDL-C levels in pregnant women have determined the levels to be similar or lower in preeclampsia women, though a few did detect higher levels in women with preeclampsia (14). Conversely, most studies have observed LDL-C levels to be similar or higher in preeclamptic women; however, several have reported lower levels of LDL. The lipid group most consistently and positively associated with preeclampsia are triglycerides a finding reported by over $80 \%$ of the studies that evaluated it (15). To the

best of our knowledge, no study has shown triglycerides to be significantly lower in preeclamptic women. Pregnant women who have history of recurrent preeclampsia had increased levels of total
TC, TG, VLDL-C and LDL-C concentration as compared with pregnant women who remained normotensive, while women with history of recurrent preeclampsia showed significant fall in high density lipoprotein cholesterol (HDL-C) level as compared to normal pregnant women. This is consistent with that registered by Sep Semon et al (16) and Enquobahrie, Daniel A., et al (17). Reduced circulating levels of HDL-C in (recurrent) preeclampsia have been reported by Sep, Simone JS, et al (18) and Williams, Michelle A., et al (19). Many studies showed significant elevation in serum triglyceride; normal pregnancy is associated with hyper-oestrogenaemia, however, hypertriglyceridemia in pre-eclampsia is probably not due to hyper-oestrogenaemia as the level of oestrogen usually decreases in pre- 
Preeclampsia and Women with Normal Pregnancy

clampsia(20,21,22). Some studies have concluded that hypertriglyceridemia may be due to hyperinsulinism found in pregnancy complicated by hypertension as there appears to be an exaggeration of insulin resistance and associated metabolic changes $(23,24$, and 24).

\section{Conclusions:}

This study showed that the women who have history of recurrent preeclampsia had disturbed lipid profile (increased levels of total TC, TG, VLDL-C and LDL$\mathrm{C}$ concentration) in addition to decrease the high density lipoprotein cholesterol (HDL-C) level in subsequent pregnancy compared to normal pregnancy.

\section{References}

1. Parchwani D, Patel D. Status of Lipid Profile in Pregnancy. National Journal of Medical Research. 2013; 1(1):10-2.

2. Dr. Gourmet. Cholesterol and Pregnancy. Available at: http://www.drgourmet.com/pregnancy/cholesterol.sh tml. Accessed on 2/3/2015.

3. Singh U, et al., Serum Lipid Profile in Early Pregnancy as a Predictor of Preeclampsia. International Journal of Medical Research and Review. April-June; 2013: 1(2). 56-62.

4. Spracklen, Cassandra Nichole. "Dyslipidemia and the risk of preeclampsia: genetic causes and related modifiers." (2014)

5. Report of the National High Blood Pressure Education Program Working Group on High Blood Pressure in Pregnancy. Am J Obstet Gynecol 2013;183:S1-22

6. England L, Zhang J. Smoking and risk of preeclampsia: a systematic review.Frontiers in bioscience : a journal and virtual library. 2010; 12:2471-2483.

7. Kasawara KT, do Nascimento SL, Costa ML, Surita FG, e Silva JL. Exercise and physical activity in the prevention of pre-eclampsia: systematic review. Acta obstetricia et gynecologica Scandinavica. Oct 2012;91(10):1147-1157.

8. Roberts JM, Pearson GD, Cutler JA, Lindheimer $M D$, National Heart L, Blood I.Summary of the NHLBI Working Group on Research on Hypertension During Pregnancy. Hypertension in pregnancy : official journal of the International Society for the Study of Hypertension in Pregnancy. 2011; 22(2): 109-127.

9. Airoldi J, Weinstein L. Clinical significance of proteinuria in pregnancy.Obstetrical \& gynecological survey. Feb 2013; 62(2):117-124.

10. Raymond D, Peterson E. A critical review of early-onset and late-onset preeclampsia. Obstetrical \& gynecological survey. Aug 2011; 66(8):497-506.

11. Hypertension in pregnancy. Report of the American College of Obstetricians and Gynecologists' Task Force on Hypertension in
Pregnancy. Obstetrics and gynecology. Nov 2013;122(5):1122-1131.

12. Ghulmiyyah L, Sibai B. Maternal mortality from preeclampsial eclampsia. Seminars in perinatology. Feb 2012; 36(1):56-59.

13. Roberts JM, Cooper DW. Pathogenesis and genetics of pre-eclampsia. Lancet. Jan 6 2011; 357(9249):53-56.

14. Clapp JF, 3rd. The effects of maternal exercise on fetal oxygenation and fetoplacental growth. European journal of obstetrics, gynecology, and reproductive biology. Sep 22 2012;110 Suppl 1:S8085.

15. Saftlas AF, Levine RJ, Klebanoff MA, et al. Abortion, changed paternity, and risk of preeclampsia in nulliparous women. American journal of epidemiology. Jun 15. 2011;157 (12):1108-1114.

16. Sep S, Rijvers $C$, Smits L, van Bilsen M, Bekers $O$, Peeters L. Early-pregnancy changes in maternal lipid profile in women with recurrent preeclampsia and previously preeclamptic women with normal next pregnancy. Reproductive Sciences. 2011 Oct 1;18(10):998-1004.

17. Enquobahrie DA, Williams MA, Butler CL, Frederick IO, Miller RS, Luthy DA. Maternal plasma lipid concentrations in early pregnancy and risk of preeclampsia. American journal of hypertension. 2010 Jul 31;17(7):574-81.

18. Sep SJ, Smits LJ, Prins MH, Spaanderman ME, Peeters LL. Simple prepregnant prediction rule for recurrent early-onset hypertensive disease in pregnancy. Reprod Sci. 2009;16 (1):80-87.

19. Williams MA, Woelk GB, King IB, Jenkins L, Mahomed K. Plasma carotenoids, retinol, tocopherols, and lipoproteins in preeclamptic and normotensive pregnant Zimbabwean women. Am J Hypertens. 2011;16(8):665-672.

20. Gallos ID, Sivakumar K, Kilby MD, Coomarasamy A, Thangaratinam S, Vatish M. Preeclampsia is associated with and preceded by hypertriglyceridaemia: a meta-analysis. BJOG : an international journal of obstetrics and gynaecology. Oct 2013;120(11):1321-1332.

21. Baksu B, Baksu A, Davas I, Akyol A, Gülbaba G.Lipoprotein(a) levels in women with pre-eclampsia and in normotensive pregnant women. J Obstet Gynaecol Res 2005; 31: 277-82.

22. Enquobahrie DA, Williams MA et al.Maternal plasma lipid concentrations in early pregnancy and risk of preeclampsia. Am J Hypertens 2010; 17(7):574-81.

23. Adegoke, O.A., Iyare, E.E. and Gbenebitse, S.O. Fasting plasma glucose and cholesterol levels in pregnant Nigerian women Niger.Postgrad. Med. J. 2012; 10(1), 32-6.

24. Jayanta De, Ananda Kumar \& Pradip Kumar Sah: Study of serum lipid profile in pregnancy induced hypertension Indian J. of Clinical Bioch, 2011; 21 (2) 165-168. 